\title{
Civil Engineering Construction Management Based on BIM Technology
}

\author{
Jin Qiaolan' ${ }^{1}$ Zhang Bin ${ }^{2}$ \\ ${ }^{1}$ Henan Technical College of Construction, Zhengzhou, Henan, China \\ ${ }^{2}$ Yellow River Institute of Hydraulic Research, YRCC, Zhengzhou, Henan, China \\ *Corresponding Author.
}

\begin{abstract}
:
The application of BIM Technology in civil engineering construction is one of the important trends of the innovation and development of the current construction market and the realization of efficient construction. Through the application of BIM Technology in civil engineering, the whole process of engineering construction can be monitored and managed, the whole civil engineering construction level can be improved, and the quality of engineering construction can be met. In this paper, through the application of BIM Technology in the construction management of construction engineering, the information technology means, visual characteristics and dynamic mode strengthening project management model based on itself are studied. In this paper, through the three-dimensional technical means to build the model, strengthen the systematic supervision of the construction project. The experimental results show that the model can better guarantee the construction completion on schedule, improve the construction quality and reduce the construction cost.
\end{abstract}

Keywords: BIM, Project Management, 3D Technical Model, Construction Cost.

\section{INTRODUCTION}

The construction industry is the pillar industry of China's national economy [1-2]. In the past 20 years of reform and opening up, the construction industry has developed rapidly and plays an important role in modern social and economic life. According to statistics, the added value of domestic construction investment in 2017 was 5568.9 billion yuan, an increase of $4.3 \%$ over 2016 [3]. However, with the rapid development of the construction industry, many problems are exposed: backward construction management mode, serious waste, project quality problems, discrete information of construction participants, etc. It is imperative to reform the traditional production organization mode and construction management mode of construction industry [4-5].

"2016-2020 outline of information development of construction industry" requires: vigorously develop BIM Technology, cloud computing, mobile communication and other information technology, realize the integrated application of BIM and enterprise information management system, speed up the popularization and application of BIM Technology, carry out data sharing and collaboration among multiple disciplines, and integrate BIM with enterprise information management system [6-8]. The digital model is applied to the whole life cycle of design, construction and operation of construction project. In the face of increasing 
industry pressure, China's construction enterprises have realized the importance of information management tools, and tried to apply information technology in the construction field, but they are limited to a certain stage and a certain aspect, and have not formed a complete information management application system. With the popularization and development of BIM Technology and virtual reality technology in the field of construction, many enterprises and professionals begin to focus on the development and research of information management platform based on BIM Technology.

\section{RESEARCH ON BIM CONSTRUCTION KANBAN MANAGEMENT SYSTEM FRAMEWORK}

\subsection{Classification of BIM construction Kanban}

In the application of Kanban management theory in manufacturing industry, according to the characteristics and operation mechanism of production management activities, Kanban is mainly divided into: transmission Kanban, production Kanban and temporary kanban. Kanban management applied in construction management can not completely copy the classification setting and operation mechanism of Kanban in production management. It should be combined with the characteristics of construction management to carry out the grading setting of construction Kanban with architectural characteristics. According to the characteristics of WBM, the construction process is divided into Kanban and kanban. The management organization structure in project construction is as follows:

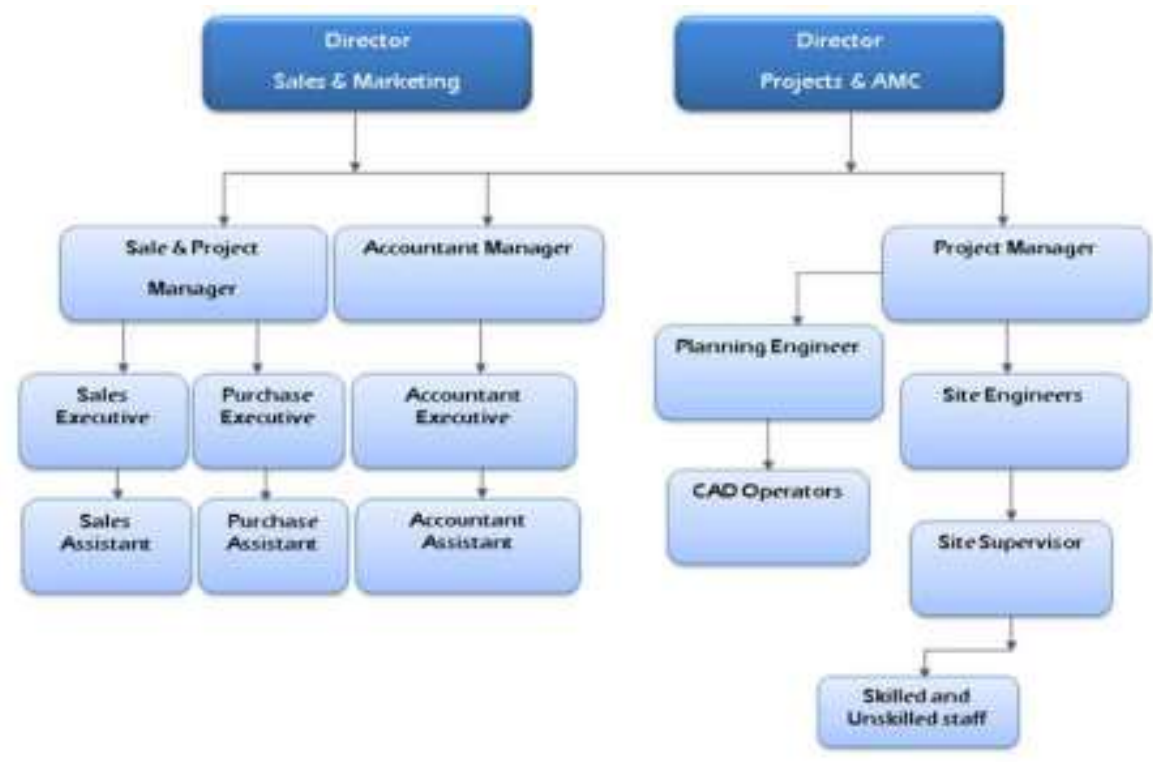

Fig 1: Management organization chart

The classification setting of BIM construction Kanban is completed by the intersection of time and object. The construction information of corresponding progress, cost, quality and safety is covered in each level Kanban according to the work responsibilities and contents of the objects used. This can meet the needs of users through identity verification to obtain the required project construction management information, and assist the user to complete the management of the construction site.

\subsection{Content design of general Kanban}

The main service object of the general Kanban is the decision-making level. The construction information about progress, cost and quality in the general Kanban should be determined according to the work 
responsibilities and contents of the users. The decision-making level is mainly responsible for organizing and formulating the overall planning and construction plan of the project, coordinating the relationship among the owner, the supervisor, the professional subcontractors and the suppliers, and ensuring the normal operation of the construction and production activities. In the project construction management activities, the main responsibilities of the decision-making level are as follows:

(1) Determine the overall objectives and stage objectives of the project, decompose the objectives of the construction project, and formulate the control plan of each construction objective.

(2) Coordinate the cooperation relationship between all participants and professional subcontractors in the process of project construction, and coordinate the cooperation relationship between technical measures and schedule control, cost control and quality control.

(3) Supervise the construction participants to ensure that the construction is organized according to the design requirements and specifications.

(4) Supervise the implementation of quality regulations, ensure the construction quality, and complete the construction progress and cost target control through project plan adjustment.

(5) The decision-making level has the power of scheme decision-making, major technical organization measures decision-making and resource allocation, and is responsible for on-site construction organization, production management, schedule arrangement, safe and civilized construction, quality control, construction, design change and other on-site management.

\section{DEVELOPMENT OF BIM CONSTRUCTION KANBAN MANAGEMENT SYSTEM}

\subsection{System function design framework}

The design framework of BIM construction Kanban management system mainly includes: interface design, model display, information query, information feedback, construction simulation and other functional modules. Each function module is developed through $\mathrm{C}$ \# script programming to realize each application function in the module. The main design framework of the system is as follows:

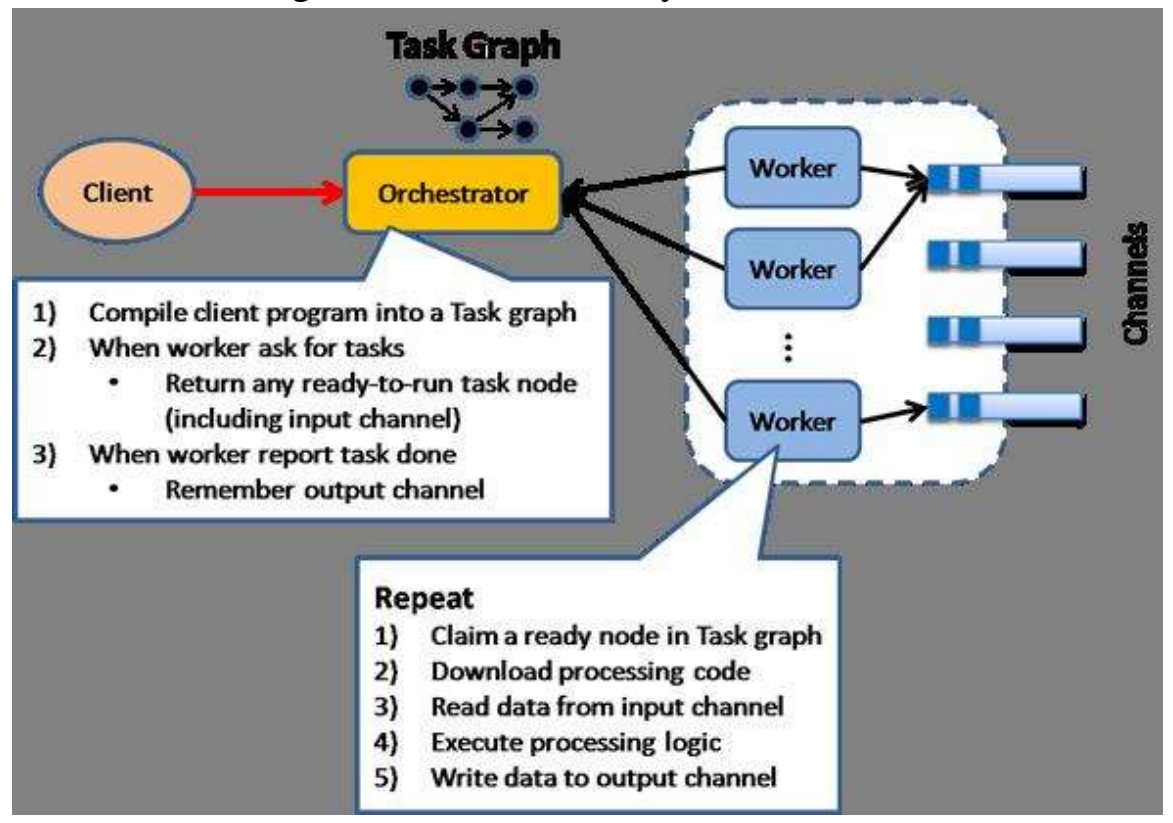

Fig 2: System design framework 


\subsection{System operation process}

BIM construction Kanban management system is developed on the basis of task division of project manager, technical director, construction team leader and other construction management personnel. Based on BIM construction Kanban management system, each module of Kanban at all levels takes progress, cost and quality as the main line to read and transfer the construction information and guide the site construction.

BIM construction Kanban management system is a kind of information storage and query platform for construction site application. According to the job responsibilities and task division of project manager, technical director and other users, functional design and development of Kanban modules at all levels are carried out. When users use the system, the specific operation process is as follows:

(1) In BIM construction Kanban management system, the construction information acquisition is based on BIM 3D model. In the system model display column, the corresponding 3D model is imported, and the user can query the construction information more intuitively.

(2) The progress information in the system is forward transmitted. The schedule formulated by the superior management can be inquired by the lower level construction management personnel and the progress information can be obtained in time. The progress module in the Kanban at all levels is set by levels, which can provide managers at all levels to obtain accurate construction progress information in time and control the construction progress on site.

(3) The quality information query of the Kanban at all levels in the system is carried out in reverse. The construction personnel on site upload the feedback and acceptance application documents, which shall be reviewed by the construction team leader, and the construction team leader shall improve the quality inspection record according to the actual situation on the site. The technical director shall review the quality inspection record and formulate the site confirmation document to verify the quantity of the project. The project manager is responsible for reviewing the site confirmation documents and the visa and change documents uploaded by the site construction personnel.

(4) Cost query module is set up for different objects in Kanban at all levels. Users can timely obtain cost information according to the query requirements and control the construction on site.

\section{ENGINEERING APPLICATION}

\subsection{Project overview}

1) Project introduction

A commercial complex project in Longkou City has three floors above ground. The first to third floors in the north are pedestrian streets, the first and second floors in the south are shopping malls, supermarkets and department stores, and the third floor is cinema. The total height of the building is $17.40 \mathrm{~m}$, the height of the first and second floors is $5.40 \mathrm{~m}$, and the third floor is divided into two parts. The height of the north part is $5.10 \mathrm{~m}$, and the south part is $6.60 \mathrm{~m}$. The building structure is frame structure with a total building area of $47376.26 \mathrm{~m}^{2}$.

\section{2) Engineering features}

The project is a key project in Longkou City, and the progress and quality of the project are concerned by the government and the people of the whole city. The construction scale of the project is large, the construction period is relatively tight, the cost control is very strict, the construction technology is complex, and the construction difficulty is relatively large. The main construction difficulties are as follows: 
(1) Progress: the project must be completed within the time limit specified in the contract without delay.

(2) Quality: because it is a key project of urban construction, engineering quality requirements are higher, we must ensure that the engineering construction quality meets the requirements of engineering acceptance specifications.

(3) Cost: strictly control the project cost according to the bill of quantities to ensure the cost deviation within $5 \%$.

\subsection{Feasibility analysis of BIM construction Kanban management system}

BIM construction Kanban management is based on BIM Technology and engineering construction related documents, with the project progress, cost, quality and safety and other construction target control as the main line, to carry out the functional design of each module of the system's total Kanban, sub Kanban, stage Kanban and process kanban. Through three-dimensional model display, click query of construction information, construction process simulation, interaction with external programs and other functional modules, users can query and obtain all kinds of construction information in time. The construction Kanban management system integrates the project management results of BIM Technology in the process of project construction, provides accurate construction information for the site and guides the site construction. This paper analyzes the application feasibility of BIM construction Kanban management system in the project from three aspects of project schedule, cost and quality:

(1) Progress

Due to the large volume of the project and tight construction period, the project must be completed within the time limit specified in the contract. In the process of construction, construction errors, rework and other emergencies, as well as weather and other external factors may lead to construction progress delay. In BIM construction Kanban management system, dynamic control of project progress can be realized based on BIM 3D model display, construction progress simulation and other functional modules. The construction management personnel take the construction Kanban management as the platform, and timely adjust the construction schedule in combination with the on-site construction situation, so as to ensure the realization of the progress goal.

(2) Cost

The project is short of funds, and the cost deviation is required to be controlled within 5\%, so as to avoid construction waste as much as possible in the construction process. BIM construction Kanban management system is based on the BIM three-dimensional model to calculate the quantities by floor and area, timely adjust the engineering model and update the quantities according to the on-site construction situation, so as to provide accurate cost information for on-site construction and realize the dynamic control of construction cost.

\section{(3) Quality}

This project is a landmark building in the city, with high quality requirements. Because it is a large commercial complex, the complexity of the building is high, and the construction is difficult, which brings some difficulties to the construction management. BIM construction Kanban management system has set up a virtual roaming module, through which the construction management personnel can roam freely in the virtual construction site, and timely find the quality defects and safety problems in the construction.

\subsection{Application ideas}

The application of BIM construction Kanban management system in the project is mainly as follows: import the project CAD drawings into the Revit software for BIM full professional turnover, and use the 
NavisWorks construction management software based on BIM full professional model for collision inspection, construction simulation, rapid increase and other operations. The information about project progress, cost, quality and safety is extracted and imported into the construction Kanban management system in the form of text, picture, form, video, 3D model and so on, and the system is filled and designed. The construction management personnel use BIM construction Kanban management system as the construction information query platform to obtain the construction management information needed in each construction stage and guide the construction. The application idea of the system is as follows:
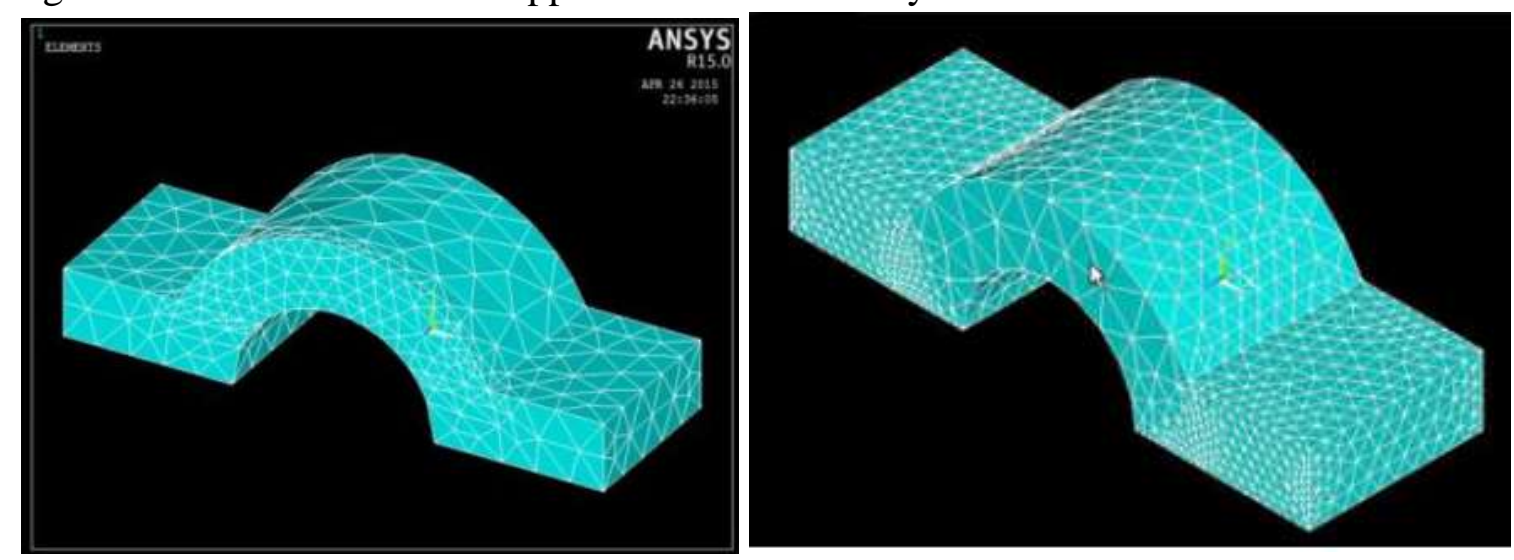

A. Axial diagram of type II surrounding rock support system

B. Bending moment diagram of class II surrounding rock support system

Fig 3: System application ideas

\subsection{Application and development of BIM construction Kanban management system}

In this section, the main functions of BIM construction Kanban management system will be designed based on the exported construction management information, with schedule, cost, quality and safety as the control objectives.

(1) Progress management

The general construction schedule module in the general Kanban has set up the schedule query navigation, and the external program function can be opened through code programming. The project manager and other users can select to query the general construction schedule, fire water project schedule and other construction progress information through the schedule query navigation function. Through BIM construction Kanban management system, a progress information transmission chain is formed between project manager and technical director, construction team leader and on-site construction personnel, which is convenient for construction management personnel to control on-site construction progress and ensure the realization of construction progress objectives.

(2) Cost management

The BIM construction Kanban management system integrates the construction cost management information extracted from the BIM 3D model. The construction management personnel can query the engineering quantity information in time through the modules of material management, cost control and onsite confirmation, so as to realize the real-time monitoring of the construction cost. According to different users, the Kanban at all levels in the system sets up the corresponding cost management information. Based on BIM Technology, the construction cost is managed hierarchically.

(3) Quality 
In BIM construction Kanban management system, in order to ensure the construction quality and reduce the occurrence of potential safety problems, construction technology disclosure and quality inspection modules and construction problem feedback modules are set up in Kanban at all levels respectively to assist relevant construction management personnel in construction quality management. In the virtual roaming module of the general Kanban, a virtual construction scene is constructed based on BIM full professional model. Through this module, project managers can have a construction simulation experience to help them grasp and understand the construction situation more vividly and intuitively.

\section{CONCLUSION}

This paper studies Kanban management theory, an advanced production management idea in manufacturing industry. Combined with the similarities and differences between manufacturing industry and construction industry, Kanban management theory is applied to construction industry based on BIM Technology, and a construction Kanban management system with construction industry characteristics is developed. Applying virtual simulation technology, with the help of $\mathrm{C}$ \# programming language and based on unity3d virtual engine platform, the BIM construction Kanban management system is designed and developed by integrating the BIM Technology output construction management information.

\section{REFERENCES}

[1] Zheng, R., Jiang, J., Hao, X., Ren, W., Xiong, F., \& Ren, Y., (2019). BcBIM: a blockchain-based big data model for bim modification audit and provenance in mobile cloud. Mathematical Problems in Engineering, 2019, 1-13.

[2] Hu, Z. Z., Tian, P. L., Li, S. W., \& Zhang, J. P., (2017). BIM-based integrated delivery technologies for intelligent mep management in the operation and maintenance phase. Advances in Engineering Software, S0965997817302533.

[3] Karan, E. P., Irizarry, J., \& Haymaker, J., (2016). BIM and GIS integration and interoperability based on semantic web technology. Journal of Computing in Civil Engineering, 30(3), 04015043.

[4] Zhang, J., (2020). Interaction design research based on large data rule mining and blockchain communication technology. Soft Computing(5).

[5] Peng, Y., Lin, J. R., Zhang, J. P., \& Hu, Z. Z., (2017). A hybrid data mining approach on BIM-based building operation and maintenance. Building and Environment, 126(dec.), 483-495.

[6] Lee, S. I., Bae, J. S., \& Cho, Y. S., (2012). Efficiency analysis of set-based design with structural building information modeling (s-BIM) on high-rise building structures. Automation in construction, 23(May), p.20-32.

[7] Diao, Y., Kato, S., \& Hiyama, K., (2011). Development of an optimal design aid system based on building information modeling. Building Simulation, 4(4), 315-320.

[8] Fortino, G., Messina, F., Rosaci, D., \& Sarne, G. M. L., (2019). Using blockchain in a reputation-based model for grouping agents in the internet of things. IEEE Transactions on Engineering Management, PP(99), 1-13. 